\title{
Bacteriological Profile of Hospital Acquired Infections with Multidrug Resistance Burden and Extended Spectrum Beta Lactamase Prevalence
}

\author{
Tarana Sarwat ${ }^{*}$, Vichal Rastogi, Mohd. Rashid and Yogesh Chander \\ Department of Microbiology, SMS\&R, Sharda University, Greater Noida, India \\ *Corresponding author
}

\begin{tabular}{|c|}
\hline Keywords \\
\hline $\begin{array}{l}\text { Hospital acquired } \\
\text { infections, Multidrug } \\
\text { resistance, Extended } \\
\text { spectrum beta } \\
\text { lactamases, Non- } \\
\text { fermenters }\end{array}$ \\
\hline Article Info \\
\hline $\begin{array}{l}\text { Accepted: } \\
\text { 10 February } 2018 \\
\text { Available Online: } \\
10 \text { March } 2018\end{array}$ \\
\hline
\end{tabular}

A B S T R A C T

Hospital acquired infections are one of the major causes of morbidity and mortality in hospitalized patients, leading to an enormous increase in the cost of hospital care and to the emergence of new health hazards for the community. The study aimed to determine the bacteriological profile of hospital acquired infections along with prevalence of multidrug resistance and extended spectrum beta lactamase (ESBL) enzymes amongst the isolates. A total of 180 isolates of various organisms were isolated from different clinical samples during a period of one year from January 2014 to December 2014. The antibiotic susceptibility testing of the isolates was done on Mueller Hinton agar using antibiotics from different classes which included beta lactams, aminoglycosides, macrolides and fluoroquinolones. Multidrug resistance was defined as resistance of the isolate to three or more classes of antibiotics. Extended spectrum beta lactamase detection was done in Gram negative isolates by the combined disc diffusion method. The isolates included Staphylococcus aureus (32.22\%), Pseudomonas aeruginosa (20.56\%), Escherichia coli (16.11\%), Coagulase negative Staphylococcus $(12.22 \%)$, Klebsiella pneumoniae (8.89\%), Acinetobacter sp. (5.56\%), Enterococcus sp. (2.78\%) and Proteus mirabilis $(1.67 \%)$. Out of these 180 isolates, 27 (15\%) isolates were found to show multidrug resistance, Pseudomonas aeruginosa and Acinetobacter being the major multidrug resistant organisms. Out of the 95 Gram negative organisms, 39 were confirmed to be ESBL producers by phenotypic method. The study concluded that the hospital strains of microorganisms are becoming more and more resistant to the currently available antibiotics. So, the antibiotics should be used more judiciously keeping the higher antibiotics in reserve which can be a solution to multidrug resistance.

\section{Introduction}

Hospital acquired infections are one of the major causes of morbidity and mortality in hospitalized patients in the present scenario, leading directly or indirectly to an enormous increase in the cost of hospital care and to the emergence of new health hazards for the community. It has been observed that the majority of such infections emerge as a result of diagnostic and therapeutic interventions such as intravenous cannulas, indwelling catheters, sophisticated life support, intravenous fluid therapy, prosthetic devices, immunosuppressive therapy, and the use of broad spectrum antibiotics (Shalini et al., 2010). The rate of hospital acquired infections varies from $2.8 \%$ to $34.6 \%$ among 
hospitalized patients (Rosenthal et al., 2006). A prevalence survey conducted under the auspices of WHO in 55 hospitals of 14 countries representing 4 WHO Regions (Europe, Eastern Mediterranean, South-East Asia and Western Pacific) showed an average of $8.7 \%$ of hospitalized patients had hospital acquired infections.

At any time, over 1.4 million people worldwide suffer from infectious complications acquired in hospital (Benenson et al., 1995). The highest frequencies of hospital acquired infections were reported from hospitals in the Eastern Mediterranean and South-East Asia Regions (11.8\% and $10.0 \%$ respectively) with a prevalence of $7.7 \%$ and $9.0 \%$ respectively in European and Western Pacific regions (Tikhomirov et al., 1987). The organisms that cause hospital acquired infections are often multidrug-resistant which poses a major public health threat. The regular use of antimicrobials for treatment therapy or prophylaxis promotes the development of resistance. Extended spectrum beta lactamases are an important cause of this resistance. The detection of ESBL-producing organisms in laboratories is a critical requirement for appropriate management of patients, infection prevention and control efforts, as well for tracking these organisms in surveillance systems.

The aim of this study was to determine the bacteriological profile of hospital acquired infections along with determination of multidrug resistance (MDR) and extended spectrum beta lactamase (ESBL) enzymes amongst the isolates.

\section{Materials and Methods}

The study was conducted in the Department of Microbiology, School of Medical Sciences and Research, Sharda Hospital, over a period of 12 months, from January 2014 to December 2014.
Various clinical samples like urine, blood, pus, sputum, endotracheal secretions, and central venous line tips were collected from patients suspected to be suffering from hospital acquired infections from various wards (including orthopaedics, surgery, medicine, gynaecology, paediatrics, ENT) and ICUs and were transported immediately to the laboratory. The specimens were processed according to standard bacteriological procedures available (Mackie and McCartney, 2006). They were inoculated on Blood agar and MacConkey agar plates and the growing organisms were identified by standard techniques. Ambiguous results were confirmed by automated VITEK 2-compact system (BioMerieux, France) following the manufacturer's instructions. Antibiotic sensitivity testing was performed on Mueller Hinton agar using antibiotics from different classes - beta lactams, glycopeptides, aminoglycosides, macrolides and fluoroquinolones. Multidrug resistance (MDR) was defined as resistance of the isolate to three or more classes of antibiotics. The CLSI recommended combined disk method involving ceftazidime and cefotaxime with and without the inhibitor clavulanic acid (30 $\mu \mathrm{g}$ ) was used to confirm the presence of ESBL in Gram negative isolates.

\section{Results and Discussion}

A total of 180 isolates of various organisms were isolated from different clinical samples of patients suffering from hospital acquired infections. Out of these 180 isolates, Staphylococcus aureus constituted the maximum proportion i.e. 58 strains $(32.22 \%)$, which was followed by 37 strains of Pseudomonas aeruginosa (20.56\%), 29 of Escherichia coli (16.11\%), 22 of Coagulase negative Staphylococcus (12.22\%), 16 of Klebsiella pneumoniae (8.89\%), 10 strains of Acinetobacter sp. $(5.56 \%)$ and least by those of Enterococcus species i.e. 5 strains $(2.78 \%)$ and 3 of Proteus mirabilis (1.67\%) (Fig. 1). 
Out of the 180 isolates, 27 (15\%) were found to show multidrug resistance which was mainly against cephalosporins, fluroquinolones and aminoglycosides. Nonfermenters ranked highest amongst the MDR organisms with $40.54 \%$ strains of Pseudomonas aeruginosa being MDR and $30 \%$ of Acinetobacter. This was followed by E. coli, 20.69\%, Klebsiella, $12.50 \%$ and $S$. aureus, $1.72 \%$. Proteus, Coagulase negative Staphylococcus and Enterococcus were not found to be multidrug resistant (Table 1).

Out of the 95 Gram negative organisms, 39 were confirmed to be ESBL producers. Amongst the ESBL producing Gram negative organisms, E. coli $(51.72 \%)$ was found to be the predominant ESBL producer followed by Klebsiella (43.75\%), Pseudomonas (37.84\%), Proteus (33.33\%) and Acinetobacter (20\%) (Table 2).

Hospital acquired infections occur worldwide, both in the developed and developing world. They are a significant burden to patients and public health and are a major cause of death and increased morbidity in hospitalized patients. Our study therefore aimed to establish the local data on the bacteriological profile of hospital acquired infections and detection of multidrug resistance burden.

In the present study, 180 isolates were obtained from samples acquired from patients who showed signs and symptoms of infection after 48 hours of admission to the hospital.

The bacteriological profile showed that $S$. aureus (32.22\%) was the predominant pathogen followed by $P$. aeruginosa $(20.56 \%)$, which was the commonest nonfermenter $(8.89 \%)$. The other organisms included Acinetobacter sp. (5.56\%), Enterococcus sp. (2.78\%) and Proteus mirabilis $(1.67 \%)$. These results were in agreement with a study of 71 patients conducted at Post Graduate Institute of Medical Education and Research (PGIMER) in Chandigarh in which it was found that $35 \%$ of the pathogens isolated from wounds and blood of patients having nosocomial infections were $S$. aureus and $24 \%$ were $P$. aeruginosa (Sunil Saggar, 2011). Another six-month study conducted in 2001 of the intensive care units (ICUs) at All India Institute of Medical Sciences (AIIMS) in New Delhi, found that 140 of 1,253 patients (11 per cent) had 152 hospital-acquired infections, where $P$. aeruginosa made up $21 \%$ of isolates, $23 \%$ were S. aureus, $16 \%$ Klebsiella spp., $15 \%$ Acinetobacter baumannii and 8\% Escherichia coli (Sunil Saggar, 2011). However, our bacteriological profile was dissimilar to the profile observed in a study in Turkey in which the most common infecting microorganism was A. baumannii (25.5\%), followed by $P$. aeruginosa (14.2\%), K. pneumoniae (8.6\%), E. coli $(8.5 \%)$ and S. aureus (8\%) (Candevir et al., 2011).

A study conducted in Ahmadabad also showed that the commonest organism isolated from all samples was E. coli (25\%) followed by Acinetobacter sp. (15.62\%), CoNS (16.40\%), Klebsiella sp. (14.06\%), Pseudomonas sp. (13.28\%), Candida sp. (4.68\%) which was different from our study (Zaveri et al., 2012). This difference in the bacteriological profile may be due to the difference in the geographical regions and also in the type of procedures conducted and the antibiotic policies being followed in different hospitals.

In our study we observed that out of the 180 isolates responsible for nosocomial infections, 27 i.e. $15 \%$ of the isolates were multidrug resistant. 
Fig.1 Bacteriological profile of hospital acquired infections - 180 isolates

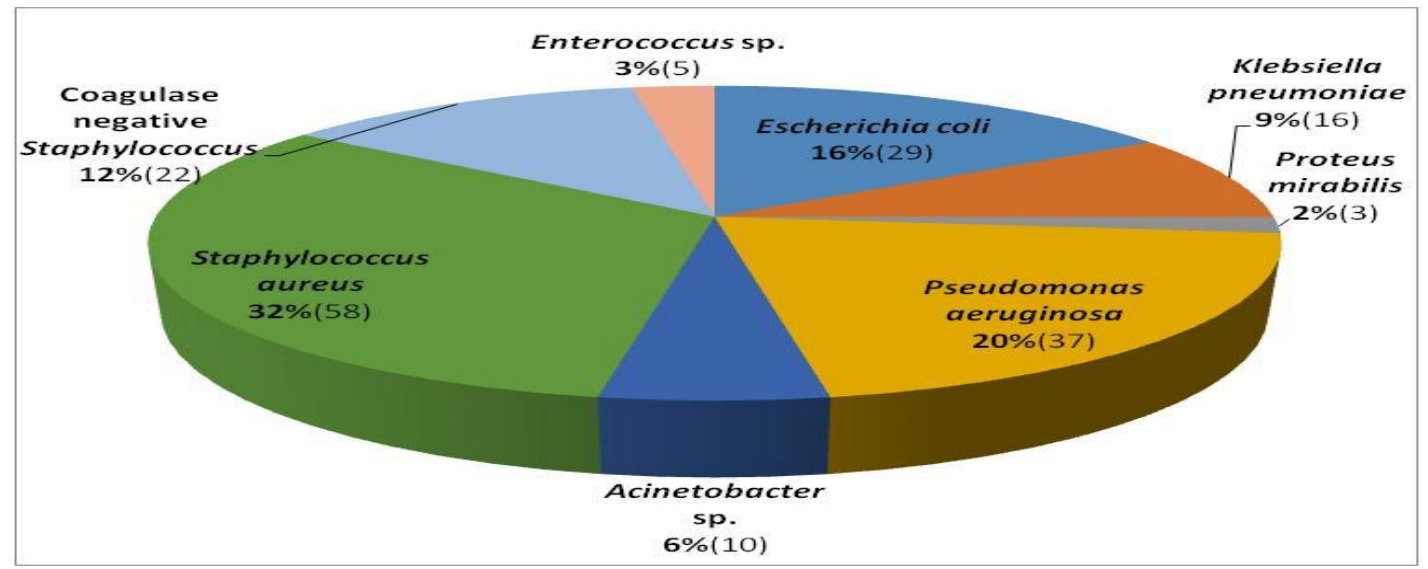

Table.1 Distribution of multidrug resistant organisms

\begin{tabular}{|l|c|c|}
\hline Organism & Number (Total) & Percentage \\
\hline E.coli & $6(29)$ & 20.69 \\
\hline Klebsiella & $2(16)$ & 12.50 \\
\hline Proteus & $0(03)$ & 0.00 \\
\hline Pseudomonas & $15(37)$ & 40.54 \\
\hline Acinetobacter & $3(10)$ & 30.00 \\
\hline S.aureus & $1(58)$ & 1.72 \\
\hline
\end{tabular}

Table.2 Distribution of ESBL producing organisms

\begin{tabular}{|l|c|c|}
\hline Organism & Number (Total) & Percentage \\
\hline E.coli & $15(29)$ & 51.72 \\
\hline Klebsiella & $7(16)$ & 43.75 \\
\hline Pseudomonas & $14(37)$ & 37.84 \\
\hline Acinetobacter & $2(10)$ & 20.00 \\
\hline Proteus & $1(03)$ & 33.33 \\
\hline
\end{tabular}

Table.3 Percentage of ESBL producing organisms in various studies

\begin{tabular}{|c|c|c|c|c|c|}
\hline $\begin{array}{l}\text { ESBL } \\
\text { producing } \\
\text { organism }\end{array}$ & $\begin{array}{l}\text { Our study, } \\
\text { India, } 2015\end{array}$ & $\begin{array}{c}\text { Bandekar } \\
\text { et al., India, } \\
2011\end{array}$ & $\begin{array}{l}\text { Oberoi et } \\
\text { al., India, } \\
2013\end{array}$ & $\begin{array}{l}\text { Tsering et } \\
\text { al., India, } \\
2009\end{array}$ & $\begin{array}{c}\text { Baharullah } e t \\
\text { al., Pakistan, } \\
2013\end{array}$ \\
\hline E.coli & 51.72 & - & 73.38 & 26.15 & 77.77 \\
\hline Klebsiella & 43.75 & 53.33 & 79.54 & 57.14 & 47.36 \\
\hline Pseudomonas & 37.84 & 44.74 & 66 & 32.61 & 46.42 \\
\hline Proteus & 33.33 & 37.5 & 50 & 42.86 & 20 \\
\hline Acinetobacter & 20 & 46. 15 & 60 & - & \\
\hline
\end{tabular}


This percentage was close to that observed in a study done in Oman which showed $11.2 \%$ of the isolates to be MDR (Balkhair et al., 2014). However, our results were different from those observed by Basnet who found $62.80 \%$ MDR organisms in their study which was much higher than that of ours (Basnet et al., 2013).

Our study showed that it were the nonfermenters which constituted the major percentage of multidrug resistant organisms amongst all the isolates. Pseudomonas aeruginosa showed $40.54 \%$ MDR which was similar to that observed in a study conducted in Nepal (41.18\%) (Basnet et al., 2013).

However other studies done in Oman (Balkhair et al., 2014) and Ahmadabad (Zaveri et al., 2012) showed lower MDR in Pseudomonas aeruginosa i.e. $8.1 \%$ and $5.89 \%$ respectively whereas studies done in Egypt (Ahmed et al., 2013) and Istanbul, Turkey (Unan et al., 2000) showed a higher percentage of MDR in Pseudomonas aeruginosa i.e. $52 \%$ and $60 \%$ respectively.

In our study, $30 \%$ of Acinetobacter isolates showed multidrug resistance which was similar to the study done in Oman i.e. $32.4 \%$ (Balkhair et al., 2014). However, Basnet (Basnet et al., 2013) showed higher percentage of multidrug resistant Acinetobacter $(89.19 \%)$ as against Zaveri who showed a lower percentage $(10 \%)$ as compared to our study (Zaveri et al., 2012).

Our study showed that $20.69 \%$ E.coli and $12.5 \%$ Klesiella were MDR. This was similar to the results of a study done in Oman which showed $18.4 \%$ and $10.3 \%$ MDR in E.coli and Klebsiella respectively (Balkhair et al., 2014). Another study done in Nepal showed a higher percentage of MDR in E.coli and Klebsiella i.e. 82.60 and $36.36 \%$ respectively (Basnet $e t$ al., 2013).
This difference in the multidrug resistance pattern of organisms in various studies may be due to difference in antibiotic policies being followed.

The prevalence of ESBLs in the Gram negative bacteria in our study was $41.05 \%$. This was quite close to a study conducted in Punjab which showed $35.16 \%$ ESBL production (Oberoi et al., 2013). Similar findings were reported in a study done by Bandekar which showed a high prevalence of the ESBL producers $(39.8 \%)$ in burn patients (Bandekar et al., 2011).

A study which was done by Harakuni reported a high prevalence of the ESBLs (74\%) in ICU patients (Harakuni et al., 2011). Study done by Laghawe and others reported 19.67\% ESBL producers (Laghawe et al., 2012). It has been proved that the prevalence of the ESBLs among the clinical isolates varies from country to country and institution to institution within the same country. In India, the prevalence rate varies in different institutions from 28 to 84\% (Das et al., 2001). A study from Coimbatore, Tamil Nadu, showed the presence of ESBLs to be $40 \%$ while from Nagpur this figure was $50 \%$ in urinary isolates (Babypadmini et al., 2004, Tankhiwale et al., 2004). Another study from New Delhi showed $68.78 \%$ of the strains of gram negative bacteria to be ESBL producers (Mohanty et al., 2005).

In our study, we found E.coli $(51.72 \%)$ to be the maximum ESBL producer followed by Klebsiella (43.75\%), Pseudomonas (37.84\%), Proteus (33.33\%) and Acinetobacter (20\%). This was in agreement with the study done by Baharullah who also observed E. coli $(77.77 \%)$ to be the major ESBL producer followed by Klebsiella (47.36\%), Pseudomonas (46.42\%) and Proteus (20\%) (Umer et al., 2013). However other studies done by Oberoi (Oberoi et al., 2013), 
Bandekar (Bandekar et al., 2011) and Tsering (Tsering et al., 2009) showed Klebsiella to be the major ESBL producer which was different from our study (Table 3).

There is no doubt that ESBL-producing infections are of grave concern to the medical world. They are associated with an increased morbidity and mortality and can be difficult and time consuming to identify. Coupled with the fact that prevalence rates are rising globally, including in nonhospital settings, and the dire lack of effective antimicrobial therapy, the future is tremendously concerning. Urgent work is required to develop quicker, cost-effective, and reliable diagnostic tools as well as new effective therapies. We hope that this study will form a useful reference for clinical microbiologists, physicians and others attempting to monitor the prevalence of hospital acquired infections and for the treatment of patients with such infections.

\section{References}

Ahmed BM, Wafaa AZ, Ghada RH, Aza ZL, Rasha G. Prevalence of MultidrugResistant Pseudomonas aeruginosa in Patients with Nosocomial Infections at a University Hospital in Egypt, with Special Reference to Typing Methods. J. Virology \& Microbiology 2013; 13 pages.

Babypadmini S, Appalaraju B. Extended spectrum $\beta$-lactamases in urinary isolates of Escherichia coli and Klebsiella pneumoniae-prevalence and susceptibility pattern in a tertiary care hospital. Indian J Med Microbiol 2004; 22: $172-174$.

Balkhair A, Al-Farsi YM, Al-Muharrmi Z, Al-Rashdi R, Al-Jabri M, Neilson F, et al., Epidemiology of Multi-Drug Resistant Organisms in a Teaching Hospital in Oman: A One-Year
Hospital-Based Study. The Scientific World Journal 2014:6 pages.

Bandekar N, Vinodkumar CS, Basavarajappa KG, Prabhakar PJ, Nagaraj P. The beta lactamases mediated resistance amongst the gram negative bacilli in burn infections. Int $\mathrm{J}$ of Bio Res 2011;2: 766-770.

Basnet BB, Dahal RK, Karmacharya N, Rijal BP. Retrospective audit of LRTI from sputum samples with respect to Acinetobacter spp., Pseudomonas spp. and Klebsiella spp. from tertiary care Hospital of Nepal. Int J Med Health Sci 2013; 2: 266-274.

Benenson AS. Control of communicable diseases manual.16th ed. Washington: American Public-Health Association, 1995.

Candevir A, Kurtaran B, Kibar F, Karakoc E, Aksu HSZ, Taşova. Invasive deviceassociated nosocomial infections of a teaching hospital in Turkey; four years' experience. Turk J Med Sci 2011; 41: 137-147.

Das A, Ray P, Garg R, Kaur B. Proceedings of the Silver Jubilee Conference. New Delhi: All India Institute of Medical Sciences; 2001. Extended spectrum beta-lactamase production in Gram negative bacterial isolates from cases of septicemia.

Harakuni S, Karadesai SG, Mutnal MB, Metgud SC. The prevalence of the extended spectrum $\beta$-lactamaseproducing clinical isolates of Klebsiella pneumoniae in the intensive care unit patients of a tertiary care hospital. Annals of tropical medicine and health 2011; 4: 96-98.

Laghawe A, Jaitly N, Thombare V. The simultaneous detection of the ESBL and the AmpC b-lactamases in gram negative bacilli. JCDR 2012; 6: 660663. 
Mackie and McCartney Practical Medical Microbiology, Tests for the identification of Bacteria, 14th Edition, Delhi: Elsevier Publication 2006:131150.

Mohanty S, Singhal R, Sood S, Dhawan B, Das BK, Kapil A. Comparative in vitro activity of beta-lactam/beta-lactamase inhibitor combinations against Gram negative bacteria. Indian $\mathrm{J}$ Med Res. 2005; 122: 425-428.

Oberoi L, Singh N, Sharma P, Aggarwal A. ESBL,MBL and Ampc $\beta$ Lactamases Producing Superbugs - Havoc in the Intensive Care Units of Punjab India. J. Clinical and Diagnostic Research 2013; 7: 70-73

Rosenthal VD, Maki DG, Salomao R, Moreno CA, Mehta Y. Device - Associated Nosocomial Infections in 55 Intensive care units of 8 Developing Countries. Ann Intern Medn 2006; 145: 582-591.

Shalini S, Kranthi K, Gopalkrishna Bhat K. The microbiological profile of Nosocomial infections in Intensive Care Unit. J. Clinical and Diagnostic Research 2010; 4: 3109-3112.

Sunil Saggar. Hospital-acquired infections high in India: Study. Medical Times. An Ala Times Media Venture 2011.

Tankhiwale SS, Jalgaonkar SV, Ahamad S, Hassani U. Evaluation of extended spectrum beta lactamase in urinary isolates. Indian J Med Res 2004; 120: 553-556.

Tikhomirov E. WHO Programme for the control of Hospital Infectio Chemiotherapia 1987; 3: 148-151.

Tsering DC, Das S, Adhiakari L, Pal R, T SK. Extended Spectrum Beta-lactamase Detection in Gram-negative Bacilli of Nosocomial Origin. J Glob Infect Dis 2009; 1: 87-92.

Umer S, Shakirullah, Aziz U, Baharullah, Hamid I, Abdul W, et al., Prevalence and antimicrobial susceptibility pattern of ESBL producing gram negative rods causing nosocomial infection. Int J Res Pharm Sci 2013; 4: 172-176.

Unan D, Gnseren F. The Resistance of P. aeruginosa Strains Isolated from Nosocomial Infections against Various Antibiotics. Mikrobiyol Bult 2000; 34: 255-260.

Zaveri JR, Patel SM, Nayak SN, Desai K, Patel P. A study on bacteriological profile and drug sensitivity \& resistance pattern of isolates of the patients admitted in Intensive Care Units of a tertiary care hospital in Ahmadabad. National j. Medical Research 2012; 2: 330-334.

\section{How to cite this article:}

Tarana Sarwat, Vichal Rastogi, Mohd. Rashid and Yogesh Chander. 2018. Bacteriological Profile of Hospital Acquired Infections with Multidrug Resistance Burden and Extended Spectrum Beta Lactamase Prevalence. Int.J.Curr.Microbiol.App.Sci. 7(03): 988-994. doi: https://doi.org/10.20546/ijcmas.2018.703.117 